Although hospital death may sometimes be unavoidable, these findings suggest that greater support may be needed to facilitate discussions and, where possible, enable patients to die in their preferred location.

\section{USE OF ANTIBIOTICS IN DETERIORATING PALLIATIVE PATIENTS - A RETROSPECTIVE ANALYSIS}

${ }^{1}$ Andrew Page, ${ }^{2}$ Clare Rayment. 'St Gemma's Academic Unit of Palliative Care, University of Leeds; ${ }^{2}$ Marie Curie Hospice, Bradford

\subsection{6/spcare-2019-mariecuriepalliativecare.37}

Background In palliative care, 24-48hr antibiotic trials are prescribed in patients who have clinically changed and may be entering the last days of life(LDOL), but where infection is considered a possible reversible factor. Does this treatment benefit or burden patients?

Aim To determine the incidence of this in hospice practice, assess survival rates and identify common predictive factors of poor response.

Method Using SystmOne, a retrospective analysis of admissions to Marie Curie Hospice, Bradford Inpatient Unit between August-October 2018 was conducted. Data was collected for all inpatients starting antibiotics including diagnosis, OACC, details of antibiotic therapy, and admission outcome (discharge/death). Patients documented to be potentially entering LDOL when therapy was initiated were identified.

Results 78 patients were admitted, of which 40\% (31/78) received antibiotics. Of those receiving antibiotics, $77 \%(24 /$ 31 had cancer and $25 \%$ (8/31)received multiple antibiotic courses. In $35 \%(11 / 31)$ cases, concerns the patient may be entering LDOL were documented when antibiotic therapy was initiated. Of these, 91\% (10/11) died during the admission. Of those who died, all had cancer; the majority with metastatic disease(8/10), Karnofsky scores $=40 \%$ (7/10), a 'Deteriorating'(5/10) or 'Unstable'(3/10) Phase of Illness and mean duration from antibiotic initiation to death was 5.4 days (range:1-12). In patients who received multiple antibiotic courses, 75\%(6/8) died during admission.

Discussion Antibiotic use in this context appears relatively common and generally has a poor outcome, suggesting treatment could be an unnecessary burden for this patient group. Metastatic cancer, Karnofsky scores $=40 \%$, an 'Unstable' or 'Deteriorating' Phase of Illness and multiple antibiotics during admission may help predict a poor response.

\section{GROWING NEED, GROWING COMPLEXITY: PROJECTIONS OF PALLIATIVE CARE NEED AND MULTI-MORTALITY IN SCOTLAND}

\footnotetext{
${ }^{1}$ Anne Finucane, ${ }^{2}$ Anna Bone, ${ }^{2}$ Simon Etkind, ${ }^{3}$ David Carr, ${ }^{4}$ Richard Meade, ${ }^{3}$ Rosalia Munoz-Arroyo, ${ }^{5}$ Sebastian Moine, ${ }^{5}$ Scott Murray, ${ }^{5}$ Aghimien lyayi-Igbinovia, ${ }^{2}$ Catherine Evans, ${ }^{2}$ Irene Higginson, ${ }^{5}$ Kirsty Boyd. 'Marie Curie Hospice Edinburgh, UK; ${ }^{2}$ Kings College London, UK; ${ }^{3}$ Information Services Division, UK; ${ }^{4}$ Marie Curie, UK; UK; ${ }^{5}$ University of Edinburgh, UK
}

\subsection{6/spcare-2019-mariecuriepalliativecare.38}

Background Due to population ageing, serious health related burden is rising. In England and Wales, the number of people requiring palliative care is projected to grow by $42 \%$ by
2040 (Etkind et al. 2017). We sought to estimate future palliative care need in Scotland, extending previous work by examining the contribution of multi-mortality (deaths from multiple conditions), to identify priorities for future service delivery.

Methods Simple linear modelling of deaths requiring palliative care from 2017-2040, using national death registry data (National Records of Scotland) and official mortality forecasts (Office of National Statistics). Palliative care need was estimated using previously defined chronic progressive illnesses, identified from i) leading cause of death; ii) contributory causes of death.

Results Using different methods, we projected that by 2040, the number and proportion of people requiring palliative care will increase, equating to between $75 \%$ (minimal estimate) and 94\% (maximal estimate) of all deaths. Deaths due to $>2$ disease groups (cancer, organ failure, dementia, other) are projected to account for $42 \%$ of all deaths by 2040 , up from $27 \%$ in 2017.

Deaths due to dementia and cancer will increase. Most deaths will occur for those aged $>85$. If current trends continue, care complexity will rise.

Conclusions Estimates of palliative care need using leading and contributing causes of death demonstrate the complexity and extent of care needs. The forthcoming rise of palliative care need in Scotland requires strategic action to prepare, including greater palliative care training provision for generalist health professionals where people reside and receive care.

\section{WHAT CHARACTERISES A GOOD DISSEMINATION/ ENGAGEMENT STRATEGY WHEN COMMUNICATING RESEARCH FINDINGS TO PATIENTS, STUDY PARTICIPANTS AND MEMBERS OF THE PUBLIC: A SURVEY OF UK-BASED RESEARCHERS' PERSPECTIVES}

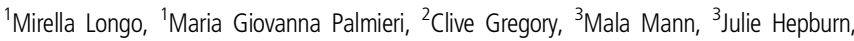
${ }^{1}$ Annmarie Nelson. 'Marie Curie Palliative Care Research Centre, Cardiff University UK; ${ }^{2}$ Division of Population Medicine, Cardiff University, UK; ${ }^{3}$ Cardiff School of Medicine, UK
}

\subsection{6/spcare-2019-mariecuriepalliativecare.39}

Background Ethical research practice requires that researchers have a clear plan about how research findings should be reported back to patients, study participants and members of the public. Communicating results solely through research journal publications is no longer sufficient. The GIRASOL study covers three stages: a review of the literature, three surveys of the public, participants and researchers, and a consensus meeting. Here we report on researchers' views around the elements of a good dissemination/engagement strategy, on their perceptions of good dissemination/engagement strategies and on what would encourage them to get more involved in dissemination and other engagement activities.

Method Content and thematic analyses were used to analyse the three open-ended questions included in the on-line survey directed to UK-based researchers.

Results 89 out of the 106 respondents addressed the openended questions. $80 \%$ of these respondents have at least six years of research record and around 30\% are/were members of funding committees. Researchers agree that when communicating results to patients/study participants, adhering to 